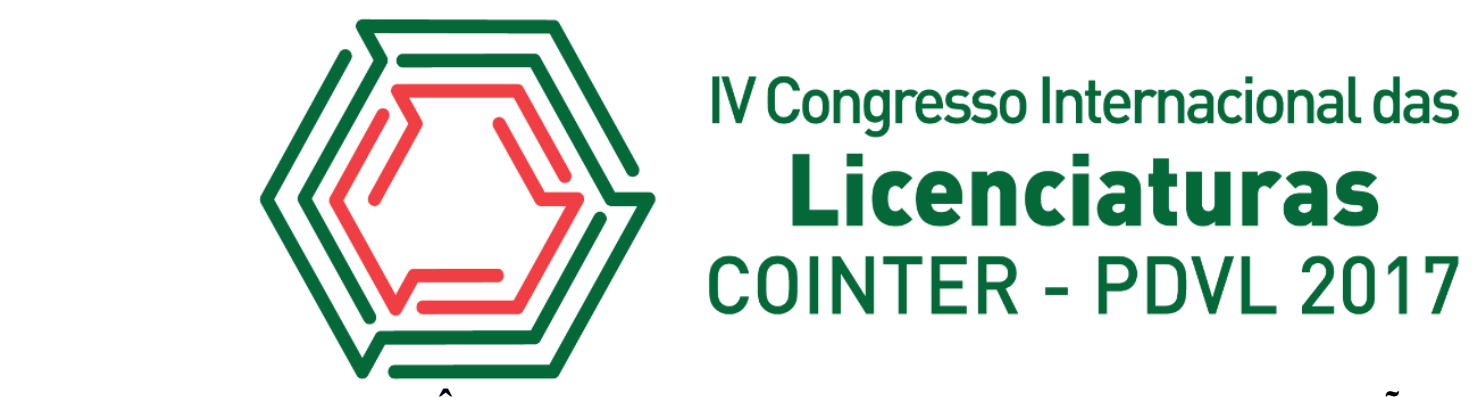

\title{
RELATO DE EXPERIÊNCIA: ATIVIDADE EXPERIMENTAL "EXPLOSÃO DE CORES" NO EVENTO SEMANA DE QÚIMICA NO IFPI-CAMPUS PICOS
}

\author{
Apresentação: Relato de Experiência \\ Rafaela Campos Sousa ${ }^{1}$; Raiany Fernanda Rodrigues²; Samuel Vitor da Silva ${ }^{3}$; Maura \\ Almeida da Silva ${ }^{4}$; Jorge Roberto de Assunção Cardoso ${ }^{5}$
}

\section{Introdução}

O Programa Institucional de Bolsa de Iniciação à Docência- PIBID proporciona à inserção do licenciando a prática do docente em plena graduação, possibilitando a articulação metodologias lúdicas que facilitem o Ensino de Química. Assim, o relato experimental foi realizado a partir de atividade à prática de ensino no curso de Licenciatura em Química, através do subprojeto PIBID em parceria com o Instituto Federal do Piauí (IFPI- Campus Picos). Com isso, a atividade experimental é uma importante ferramenta metodológica que tem por intuito envolver os alunos, com a finalidade de motiva-los e coloca-los em situações-problemas que tenham um caráter investigativo, tornando-o autor do seu próprio conhecimento.

Nesse sentido, a experimentação pode contribuir no desenvolvimento da aprendizagem dos discentes, porém a articulação e o planejamento são fundamentais para a realização da prática. Segundo Santos e Schnetzler (1996), a importâncias na inserção da atividade experimental está na distinção de seu papel nos processos investigativos e com a função da assistência aos discentes na apreensão de fenômenos químicos. Dessa maneira, a experimentação contribui em mobilizar os estudantes no processo investigativo, com intuito de enriquecer os conhecimentos científicos.

\section{Relato de Experiência}

O relato foi realizada no Instituto Federal do Piauí- IFPI- Campus Picos, localizado no município de Picos-PI, com apoio do subprojeto PIBID/Química no evento Semana da Química. Nesse sentido, a estratégia de ensino atendeu o corpo discente da referida instituição, onde a atividade experimental proporcionou um momento de reflexão dos conceitos da química através da amostra

\footnotetext{
${ }^{1}$ Licenciatura em Química, Instituto Federal do Piauí, rhacampos20@hotmail.com

2 Licenciatura em Química, Instituto Federal do Piauí, raianyfer20@hotmail.com

${ }^{3}$ Licenciatura em Química, Instituto Federal do Piauí, samuelvictorfs95@gmail.com

${ }^{4}$ Licenciatura em Química, Instituto Federal do Piauí, maura_almeida_sal@hotmail.com

${ }^{5}$ Mestre, Instituto Federal do Piauí, jracardoso@ifpi.edu.br
} 
cientifica.

Nessa perspectiva, a atividade experimental forma produzidos com reagentes de baixo custo, como: leite, detergente e corante. Assim, na imagem 1, observamos a interação do detergente em contanto com o leite, dissolvia a gordura presente, assim contribuído na interação de cores através dos corantes. Esse experimento era elucidados aos participantes presentes na mostra cientifica. Portanto, foi perceptível a participação e integração dos participantes a atividade experimental, contribuído para o enriquecimento dos conhecimentos científicos.

Imagem 1: atividade experimental. Fonte: autoria própria

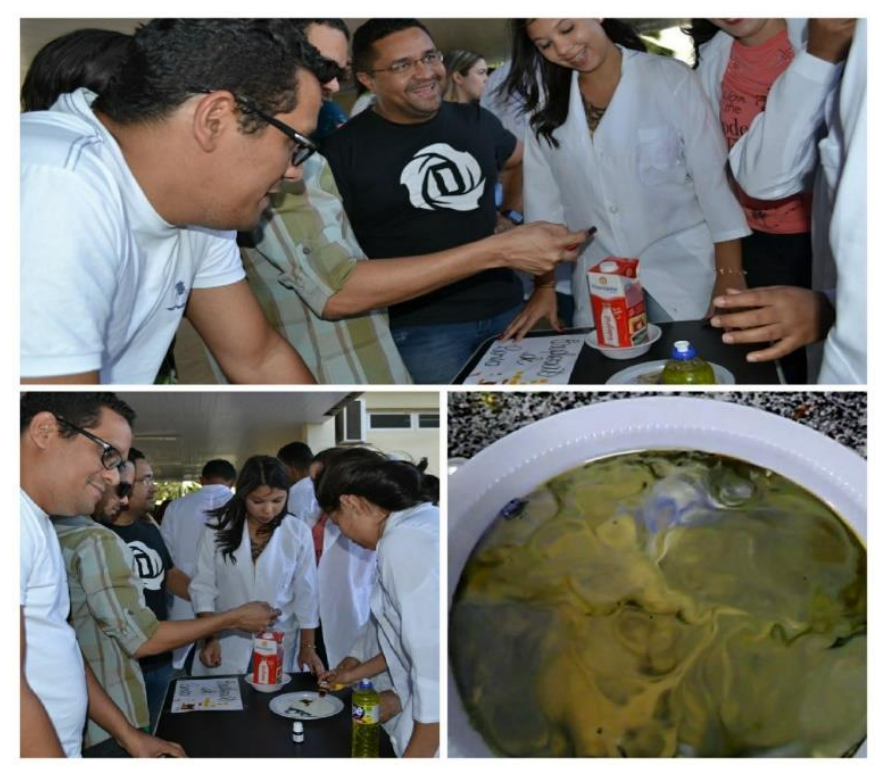

\section{Considerações}

Conclui-se que as atividades experimentais relacionado ao Ensino de Química, é notável a potencialidade para inserção do conhecimento cientifica. O uso desse recurso didático quando bem planejado e articulado, a aprendizagem mais proveitosas, participativas e motivadoras, assim facilitando a assimilação dos conteúdos, tonando possível distorcerem essa ideia de que a Química é uma disciplina complicada.

\section{Referências}

SANTOS, W. L. P.; SCHNETZLER, R. P. Função social: o que significa ensino de química para formar o cidadão? Química Nova na Escola pesquisa. n.4, p. 28-34, nov 1996. 